\title{
Effect of Application Rate and Timing on Residual Efficacy of Pyraclostrobin in the Control of Pepper Anthracnose
}

\author{
Y. Y. Gao, ${ }^{1}$ X. X. Li, ${ }^{2}$ L. F. He, ${ }^{1}$ B. X. Li, ${ }^{1}$ W. Mu, ${ }^{1}$ and F. $\mathrm{Liu}^{2,}{ }^{\dagger}$ \\ ${ }^{1}$ Shandong Provincial Key Laboratory for Biology of Vegetable Diseases and Insect Pests, Shandong Agricultural University, \\ Tai'an, Shandong 271018, People's Republic of China \\ ${ }^{2}$ College of Plant Protection, Shandong Agricultural University, Tai'an, Shandong 271018, People's Republic of China
}

\begin{abstract}
Anthracnose is a devastating disease that seriously affects pepper production worldwide. Anthracnose management is currently a major problem because of the widespread and long period of infection of this disease. Therefore, determination of the optimal fungicide application timing is important for controlling anthracnose in a timely manner. In vitro sensitivity tests showed no significant difference in the pyraclostrobin sensitivity of Colletotrichum scovillei collected from 2016 and 2017, with mean half maximal effective concentration values of 0.349 to 0.542 and 0.0475 to $0.0639 \mathrm{mg} /$ liter for the inhibition of mycelial growth and spore germination, respectively. Fungicide application initiated at the full-bloom stage could significantly delay anthracnose disease onset,

pyraclostrobin, was detected in pepper fruit and exhibited high inhibitory activity against $C$. scovillei. The final residues of all fungicides at different application timing were below maximum residue limits. Moreover, structural equation modeling indicated that application timing plays the most important role in anthracnose disease inhibition. The tank mixtures of pyraclostrobin with tebuconazole and fludioxonil showed more satisfactory efficacy ( 69.87 to $78.36 \%$ ) against anthracnose than did pyraclostrobin alone under field conditions. This study is the first to determine the best fungicide application timing for anthracnose management. These results establish the basis for sustainable development of the pepper industry.
\end{abstract} decrease anthracnose incidence and development (23.67 to $89.80 \%$ ), and increase pepper yield by 10.7 to $29.2 \%$. In addition, the application dosage was decreased by $>50 \%$. BF-500-3, the main metabolite of
Keywords: pepper anthracnose, application timing, residue level, structural equation modeling
Pepper is one of the most important economic crops in China, with a large cultivated area of 1.3 million hectares (Diao et al. 2017; Food and Agriculture Organization of the United Nations 2015). However, the pepper industry in China is also influenced by a variety of diseases (Lewis Ivey et al. 2004). Anthracnose, caused by Colletotrichum scovillei, is one of the most destructive diseases in pepper (Xia et al. 2012). In particular, the prevalence of wet, hot, and windy weather during pepper growth promotes the development of anthracnose, which has resulted in $>40 \%$ yield losses (Harp et al. 2008; Kwon and Lee 2002; Lin et al. 2004).

C. scovillei mainly infects fruit and reduces its quality. Chemical control is currently the major measure for controlling pepper anthracnose in China (Xu et al. 2014). In practice, farmers follow a fungicide application calendar or utilize a disease forecasting model (Kim and Park 1988) to regulate fungicide applications during the fruit growth stage. However, fungicides applied >10 times (Harp et al. 2014), mainly at the fruit stage, did not prevent the infection and spread of disease in a timely manner. Thus, reducing the infection source is important for the effective management of anthracnose. Colletotrichum spp. are weak parasitic and wind-dispersed pathogens that often lurk in flowers and pedicels (Lin and Hand 2019; Takushi et al. 2013). Infection and dispersal occur when the weather conditions are appropriate (Yu et al. 2013). Whether flowering is the best time

${ }^{\dagger}$ Corresponding author: F. Liu; fliu@sdau.edu.cn

Funding: This work was supported by the National Key R\&D Program of China (grant 2016YFD0200500) and the Provincial Key Research and Development Program of Shandong (grant 2017CXGC0207).

*The $\boldsymbol{e}$-Xtra logo stands for "electronic extra" and indicates that one supplementary table is published online.

The author(s) declare no conflict of interest.

Accepted for publication 26 July 2019.

(C) 2020 The American Phytopathological Society for fungicide application to prevent the infection of Colletotrichum spp. remains unknown.

With increasing concern about environmental pollution and food safety, systemic fungicides applied at the appropriate timing to reduce pesticide applications have become more important (Mueller et al. 2009). Previous studies also demonstrated that fungicides applied at the best time not only provide more satisfactory efficacy against disease but also reduce cost and improve fruit quality (Beck et al. 2014; Mueller et al. 2009). Pyraclostrobin, a locally systemic strobilurin fungicide (Forster et al. 2006; Fulcher et al. 2014), had high inhibitory activity against $C$. scoville $i$ and was selected as the tested fungicide in this study (Gao et al. 2017). BF-500-3, the main metabolite of pyraclostrobin, was assumed to have similar toxicity as that of pyraclostrobin (You et al. 2012). However, previous reports demonstrated that C. cereale (Young et al. 2010) and C. gloeosporioides (Takushi et al. 2014) developed resistance to azoxystrobin (a quinone outside inhibitor), which highlighted the importance of fungicide sensitivity monitoring. The mixture of pyraclostrobin with commonly used fungicides, including fludioxonil, tebuconazole, thiophanate-methyl, and carbendazim, also showed synergistic effects against $C$. scovillei in vitro (Gao et al. 2017), but little is known about their field efficacy.

Hence, the objectives of this study were to evaluate the sensitivity changes of $C$. scovillei to pyraclostrobin and to determine the best fungicide application timing for controlling pepper anthracnose. The residues of pyraclostrobin, picoxystrobin, and pyraclostrobin metabolite BF-500-3 in pepper fruit were determined. Structural equation modeling was established to assess the dominant factor in determining anthracnose disease severity. The efficacy of optimal tank mixtures of pyraclostrobin and fungicides with other modes of action in controlling pepper anthracnose was also determined.

\section{Materials and Methods}

Fungal isolates. During epidemics of pepper anthracnose in 2016 and 2017, isolates of $C$. scovillei were isolated from diseased fruits with typical symptoms of anthracnose from Jining, Heze, Weifang, Dezhou, Tai' an, Linyi, Yantai, and Jinan, the major pepper production regions in Shandong Province in China. A total of 160 single 
spore isolates (71 from 2016 and 89 from 2017) were collected and maintained on potato dextrose agar (PDA) slants at $4{ }^{\circ} \mathrm{C}$ until use. These tested isolates were identified based on morphology and on ITS, GAPDH, ACT, TUB2, CAL, and CHS-1 sequences according to the prescribed key of Diao et al. (2017).

Sensitivity of $\boldsymbol{C}$. scovillei to pyraclostrobin. Sensitivity tests were based on the measurement of mycelial growth on PDA plates and of spore germination on water agar (WA) plates (20 $\mathrm{g}$ of dextrose and $10 \mathrm{~g}$ of agar/liter of distilled water) (Gao et al. 2017). In the mycelial growth assay, mycelial plugs cut from the 7-day-old colony were transferred to PDA plates amended with pyraclostrobin at 0 , $0.01,0.02,0.04,0.1,0.4$, and $1.6 \mathrm{mg} /$ liter. Salicylhydroxamic acid, an inhibitor of the alternative oxidase respiration pathway, was added to ensure the accuracy of the test results (Gao et al. 2017). Plates with an appropriate volume of organic solvent were used as controls. After incubation for 6 days at $25^{\circ} \mathrm{C}$ in the dark, the mean diameter of each isolate was calculated.

In the spore germination assay, spores were scraped from the 7day-old colony using sterile distilled water and yielded a final concentration of $1 \times 10^{5} / \mathrm{ml}$. Spore suspensions $(100 \mu \mathrm{l})$ were spread on $9-\mathrm{cm}$ WA plates amended with $0,0.0025,0.005,0.01,0.02$, 0.04 , and $0.08 \mathrm{mg}$ of pyraclostrobin/liter. After incubation for 10 $\mathrm{h}$, the spore germination was determined. Spores were considered to be germinated when the germ tube length exceeded half the spore length. All experiments were repeated three times with four replicates.

Field experiments. The field experiment was conducted in 2016 and 2017 in Tai' an in Shandong Province, China. The weather conditions of the sampling year during the trials are shown in Figure 1. The experimental sites had a long history of pepper cultivation, and anthracnose disease was endemic. The field experiment sites were managed according to normal agronomic practices, and the pepper seedlings (a cultivar of Jingxinhong) were transplanted in early May.

Twenty treatments were arranged according to a randomized block design with four replicate plots. Five treatments, including pyraclostrobin $(45,90$, and $180 \mathrm{~g}$ of active ingredient [a.i.]/ha), picoxystrobin (180 $\mathrm{g}$ of a.i./ha), and a water control group, were applied at the following growth stages: $\mathrm{R} 1+\mathrm{R} 2+\mathrm{R} 3+\mathrm{R} 4, \mathrm{R} 2+\mathrm{R} 3+\mathrm{R} 4$, and $\mathrm{R} 3+\mathrm{R} 4$, where $\mathrm{R} 1$ is the full-bloom stage, $\mathrm{R} 2$ is the early green-ripening stage, R3 is the middle green-ripening stage, and R4 is the late green-ripening stage. Fungicides were applied with a backpack sprayer (MATABI-16) at $0.3 \mathrm{MPa}$ pressure, and the spray volume was 675 liters/ha. To avoid cross-contamination, $0.5-\mathrm{m}$ intervals were left between treatments. In each plot, five plants (approximately 300 fruits) were randomly selected to determine anthracnose disease severity using the following scale: 0 , no disease; 1,1 to $10 \% ; 2,11$ to $20 \% ; 3,21$ to $30 \% ; 4,31$ to $40 \% ; 5,41$ to $50 \% ; 6,51$ to $60 \% ; 7,61$ to $70 \% ; 8,71$ to $80 \%$; and $9,>81 \%$ of fruits covered with lesions. Disease severity was determined at $1 \mathrm{~h}$ and at $3,7,10$, and 14 days after the last fungicide application.

Residual determination of pyraclostrobin and its metabolites in pepper fruits. The residual levels of pyraclostrobin, picoxystrobin, and BF-500-3 at different application timing were determined when the fruit $(2 \mathrm{~kg})$ was sampled from the $\mathrm{R} 1+\mathrm{R} 2+\mathrm{R} 3+\mathrm{R} 4$, $\mathrm{R} 2+\mathrm{R} 3+\mathrm{R} 4$, and $\mathrm{R} 3+\mathrm{R} 4$ treatment groups at $1 \mathrm{~h}$ and at 1, 3, 5, 7,

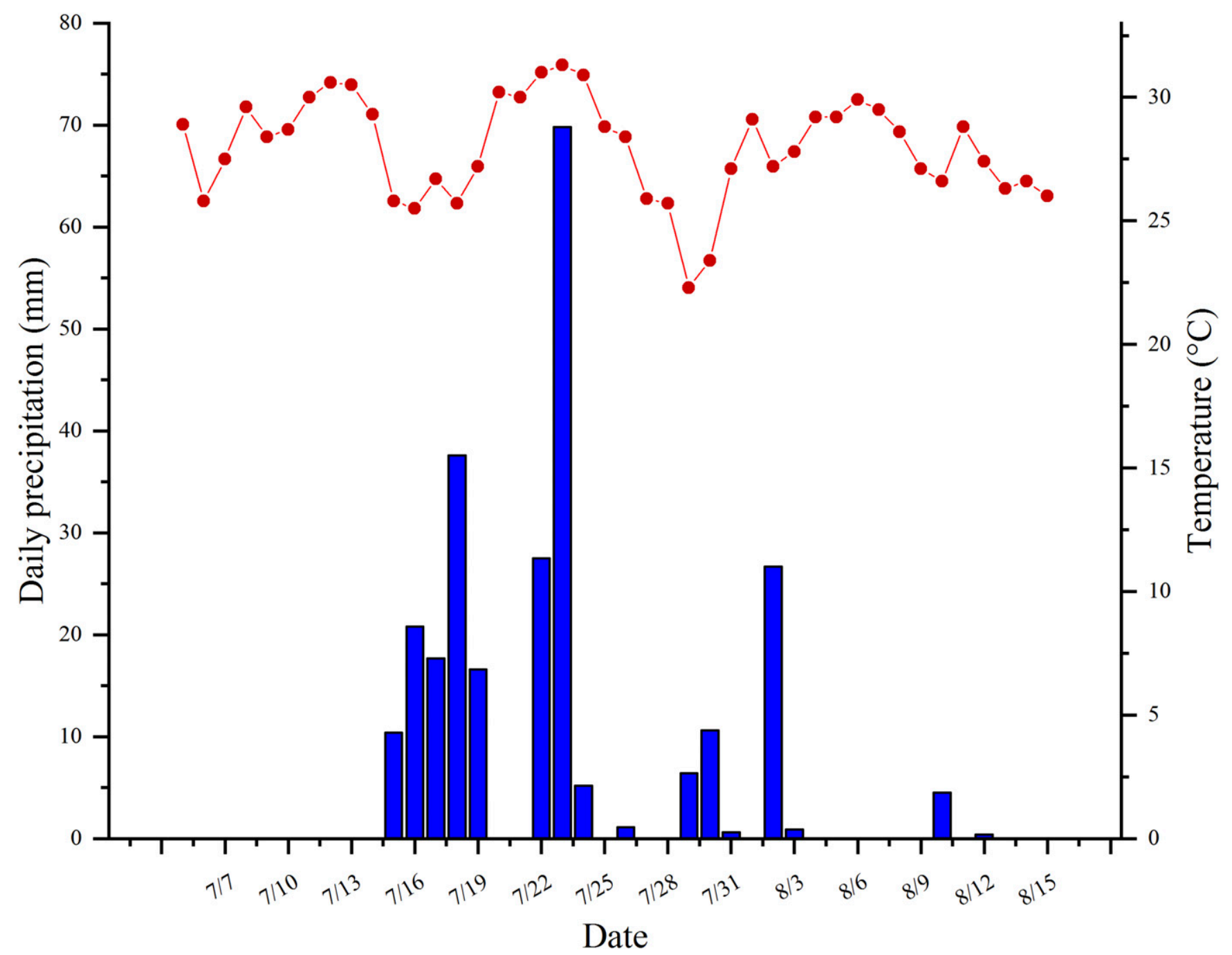

Fig. 1. Weather conditions at experimental sites in 2017. 
10, and 14 days after the last fungicide application. Fruits collected from each treatment at harvest time were used to determine the final fungicide residues. All pepper samples were stored at $-20^{\circ} \mathrm{C}$ until analysis. Extraction, clean up, detection procedures, and recovery tests were performed according to You et al. (2012) with some modifications (Supplementary Table S1).

Yield analysis. At harvest time (mid-September), 20 plants were selected from each plot to evaluate the effect of fungicide application rate and timing on pepper yield. The number of fruits per plant was counted by the standards of the current market. The harvest fruits were air-dried for approximately 7 days until they reached a constant weight. Fruit length, fruit width, and individual fruit weight (20 fruits per plot) were measured. The weight of the peppers for each plot was then determined and converted to tons per hectare.

BF-500-3 activity against $C$. scovillei in vitro. BF-500-3 biological activity on mycelial growth, spore germination, and germ tube elongation was tested by using three isolates of C. scovillei (JB6, $\mathrm{HZ8}$, and DZ10). In the mycelial growth assay, mycelial plugs were inoculated on PDA plates amended with BF-500-3 at 0, 0.05, 0.25, $0.5,2.5,5$, and $10 \mathrm{mg} / \mathrm{liter}$. In the spore germination and germ tube elongation assays, $100-\mu \mathrm{l}$ spore suspensions were spread on WA plates amended with $0,0.0125,0.025,0.05,0.1,0.4$, and $0.8 \mathrm{mg}$ of BF-500-3/liter. After incubation for $10 \mathrm{~h}$ at $25^{\circ} \mathrm{C}$ in the dark, the germ tube length ( 20 germinated spores per plate) was measured under a microscope. All experiments were repeated three times with four replicate plates. In addition, the effect of BF-500-3 on C. scovillei morphology was observed under a microscope.
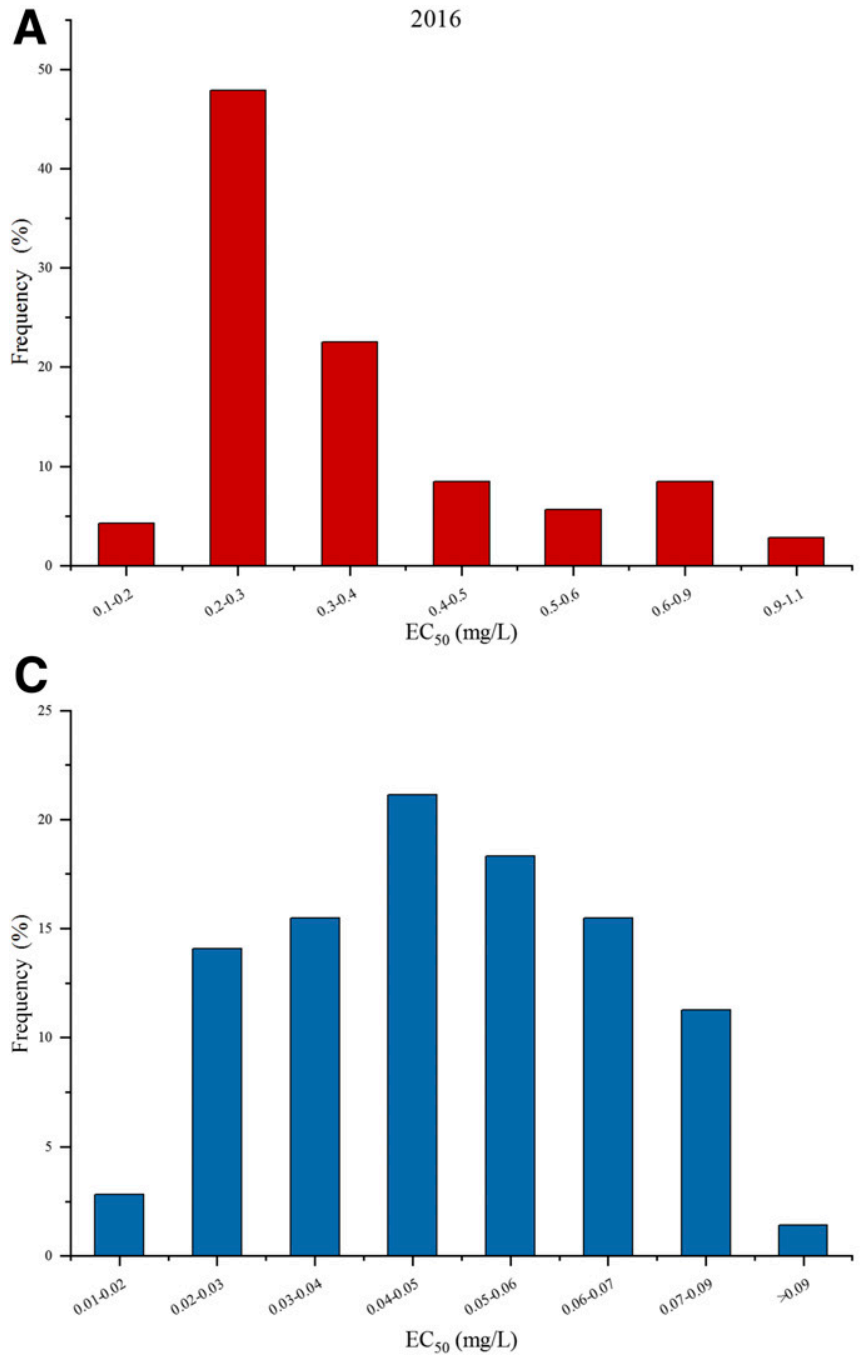

Efficacy of the mixture of pyraclostrobin and fungicides with other modes of action against pepper anthracnose in the field. The field experiments were performed as described above in 2016 and 2017. Pepper plants were sprayed with five fungicide groups, including pyraclostrobin plus fludioxonil (each $120 \mathrm{~g}$ of a.i./ha), pyraclostrobin plus tebuconazole (each $120 \mathrm{~g}$ of a.i./ha), pyraclostrobin plus thiophanate-methyl (120 and $360 \mathrm{~g}$ of a.i./ha, respectively), pyraclostrobin plus carbendazim (120 and $360 \mathrm{~g}$ of a.i./ha, respectively), and pyraclostrobin (120 g of a.i./ha). Fungicides were applied at the early green-ripening stage of fruit three times at 10-day intervals. Disease severity was assessed according to the scale described above 10 days after the last fungicide application. Control efficacy was calculated as follows:

$$
\begin{aligned}
\text { Control efficacy }(\%)= & (\text { Disease severity of control } \\
& - \text { Disease severity of treatment }) / \\
& \text { Disease severity of control } \times 100 \% .
\end{aligned}
$$

Statistical analysis. All statistical analyses were performed using SPSS software (version 20.0; IBM Corp.). Half maximal effective concentration $\left(\mathrm{EC}_{50}\right)$ values were determined by completing a regression analysis of the relative growth rate against $\log _{10}$ fungicide concentrations. The difference between each treatment was determined by analysis of variance using Tukey tests. Data expressed as percentages were arcsine transformed before analysis.

To evaluate whether residue level mediated the direct effect of fungicide application timing, dosage, and investigation date on

Fig. 2. Sensitivity of Colletotrichum scovillei to pyraclostrobin from 2016 to 2017 based on $A$ and $C$, mycelial growth and $B$ and $D$, spore germination. $E_{50}=$ half maximal effective concentration 
anthracnose disease severity or the indirect effect, structural equation modeling was performed using IBM SPSS Amos. Anthracnose disease severity was the dependent variable, and application timing, dosage, and investigation date were the independent variables. Residue was regarded as a mediator variable.

\section{Results}

Sensitivity of $C$. scovillei to pyraclostrobin. In vitro sensitivity tests showed no significant difference in the sensitivity of $C$. scovillei collected from 2016 and 2017 to pyraclostrobin. Based on mycelial growth, $\mathrm{EC}_{50}$ values for pyraclostrobin ranged from 0.177 to 1.098 and 0.143 to $1.813 \mathrm{mg} /$ liter, with average $\mathrm{EC}_{50}$ values of $0.349 \pm$ 0.152 and $0.542 \pm 0.218 \mathrm{mg} /$ liter for isolates from 2016 and 2017 , respectively (Fig. 2A and B). For the spore germination assay, $\mathrm{EC}_{50}$ values for isolates collected from 2016 and 2017 ranged from 0.0126 to 0.0835 and 0.021 to $0.112 \mathrm{mg} / \mathrm{liter}$, with average $\mathrm{EC}_{50}$ values of $0.0475 \pm 0.008$ and $0.0639 \pm 0.014 \mathrm{mg} /$ liter, respectively (Fig. $2 \mathrm{C}$ and $\mathrm{D})$. Figure 3 shows no significant difference in $\mathrm{EC}_{50}$ values between 2016 and 2017. A few abnormal values did not affect the normal distribution of $\mathrm{EC}_{50}$ values.

Inhibitory activity of BF-500-3 against $\boldsymbol{C}$. scovillei. BF-500-3, the main metabolite of pyraclostrobin, exhibited significant inhibition of mycelial growth, spore germination, and germ tube elongation of $C$. scovillei, with mean $\mathrm{EC}_{50}$ values of $1.01 \pm 0.136,0.255 \pm$ 0.037 , and $0.101 \pm 0.030 \mathrm{mg} /$ liter, respectively (Fig. 4). The normal development of $C$. scovillei was seriously affected by BF-500-3.
After BF-500-3 treatment, many short branches appeared at the end of hyphae, and the internode length of mycelium increased. In addition, most of the conidia treated with BF-500-3 did not germinate, the germ tube became short and thickened, and the tips of the tube were swollen (Fig. 4).

Effect of pyraclostrobin on anthracnose disease severity and pepper yield at different application timings. Anthracnose disease severity in the fungicide treatment groups was much lower than that in the untreated control group (Fig. 5). Fungicide applications initiated at the flowering stage significantly delayed anthracnose disease onset (anthracnose symptoms did not appear at the early greenripening stage) and decreased the development of disease severity by 1.59 to $4.08,1.78$ to 4.71 , and 1.93 to $5.93 \%$ for pyraclostrobin (180, 90, and $45 \mathrm{~g}$ of a.i./ha, respectively) and by 1.88 to $5.81 \%$ for picoxystrobin (180 $\mathrm{g}$ of a.i./ha), which exhibited more satisfactory control efficacy than fungicides applied at the early greenripening stage or middle green-ripening stage. Disease severity dramatically increased 7 days after the last fungicide application, especially in the untreated control group and the plots treated with fungicides twice, which indicated that fungicides applied at the fruit stage could not prevent the spread of disease in a timely manner. Pyraclostrobin showed higher activity against pepper anthracnose than did picoxystrobin at the same dosage.

The residue levels of pyraclostrobin and picoxystrobin decreased at later sampling dates, with concentrations of 1.43 to $4.02,0.96$ to 3.05 , and 0.77 to $2.55 \mathrm{mg} / \mathrm{kg}$ for pyraclostrobin $(180,90$, and $45 \mathrm{~g}$

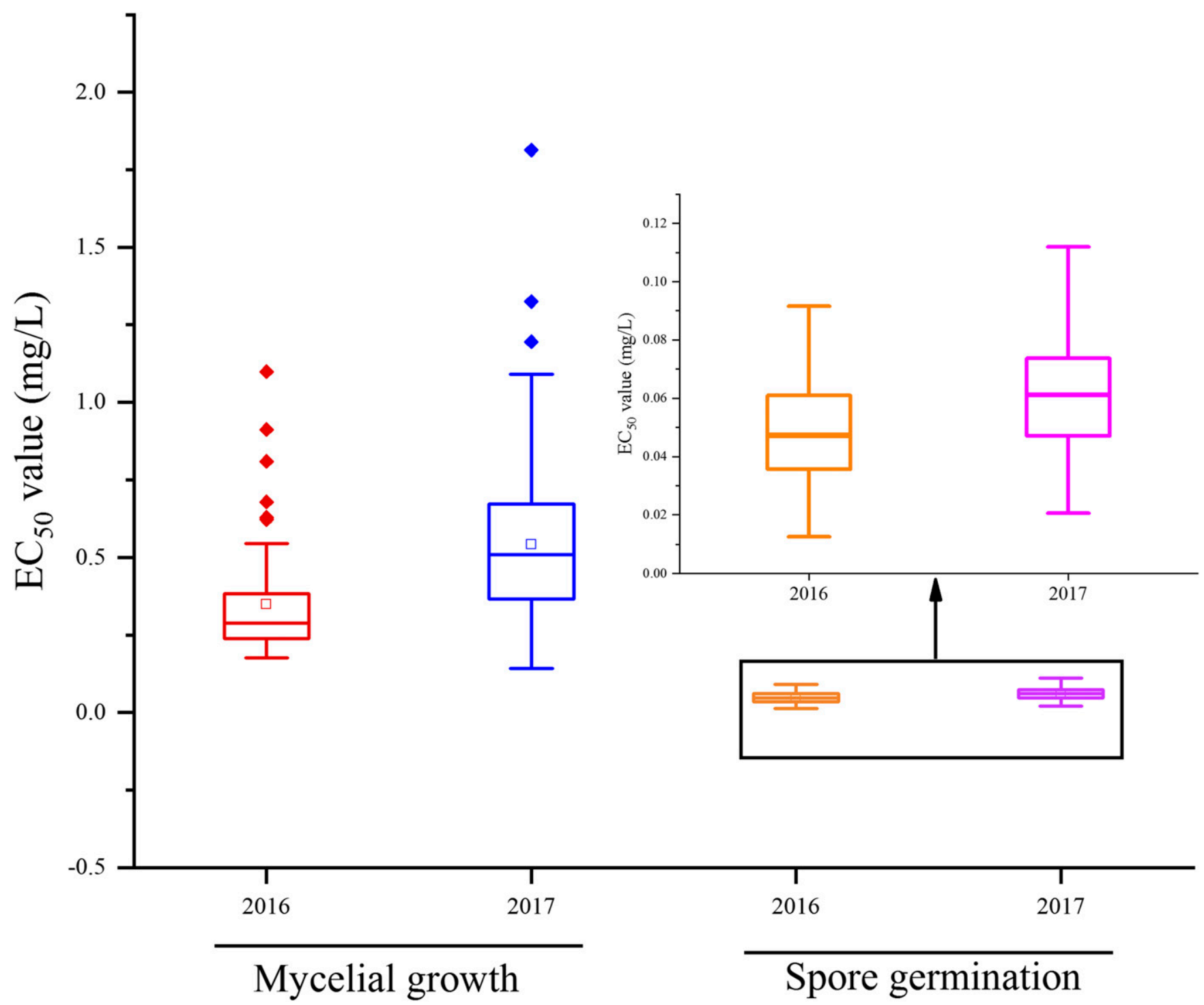

Fig. 3. Sensitivity variation of Colletotrichum scovillei to pyraclostrobin. $\mathrm{EC}_{50}=$ half maximal effective concentration. 
of a.i./ha, respectively) and 0.92 to $3.13 \mathrm{mg} / \mathrm{kg}$ for picoxystrobin (180 g of a.i./ha) during the 1-h to 14-day sampling period. The residue of BF-500-3, the major metabolite of pyraclostrobin, first increased and then decreased with levels of 0.095 to $1.18 \mathrm{mg} / \mathrm{kg}$ (Fig. 6). The higher residue levels of pyraclostrobin and the strong bioactivity of BF-500-3 indicated the more satisfactory efficacy of pyraclostrobin against pepper anthracnose than picoxystrobin. Meanwhile, the dynamic changes in pyraclostrobin residue had a positive correlation with the efficacy of pyraclostrobin in controlling anthracnose disease (Fig. 6).

Figure 7 shows the relationship among fungicide application timing, dosage, residue, and investigation date on anthracnose disease severity. The results indicated that application timing, dosage, and investigation date had significant effects on fungicide residue level, but no indirect effects of the three factors on disease severity were mediated by fungicide residue level $(-0.786, P=0.488)$. Moreover, application timing $(-3.195, P<0.001)$ and investigation date $(0.454, P<$ 0.001 ) had a significant direct effect on disease severity, indicating that application timing is of great significance. In addition, compared with application timing, dosage had little effect on disease severity.

Compared with the control, all of the treatments increased fruit yield by 1.7 to $29.2 \%$ (Table 1 ). The fruit number and the maximum fruit weight were obtained after treatment with pyraclostrobin started at the flowering stage in all tested concentrations ( $n=62.10$ to 64.10 ; 2.69 to $2.88 \mathrm{~g}$ ), with pyraclostrobin applied at $180 \mathrm{~g}$ of a.i./ha at the early green-ripening stage ( $n=63.40 ; 2.72 \mathrm{~g}$ ), and with picoxystrobin at the flowering stage $(n=61.80 ; 27.93 \mathrm{~g})$. There were no significant differences in the length and width of fruits among all treatments $(P \geq 0.136 ; P \geq 0.614)$, although the fruit number showed differences demonstrating that pyraclostrobin promoted fruit

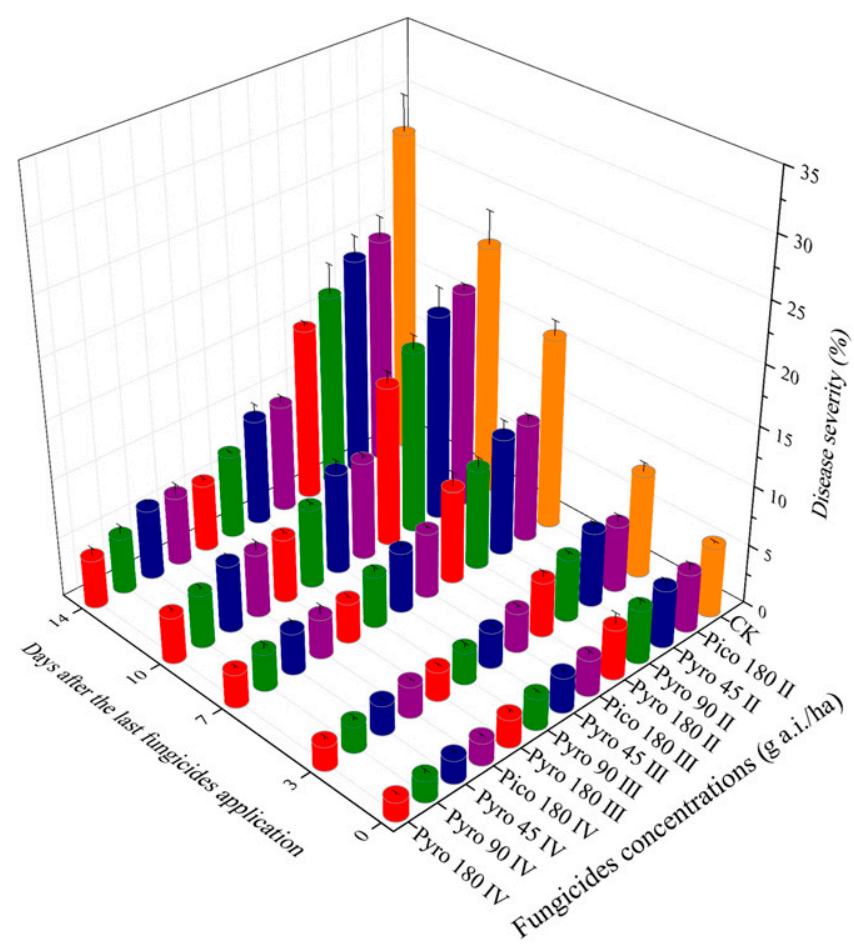

Fig. 5. Anthracnose disease severity at different application timing. II, III, and IV are the mean numbers of fungicide applications. $\mathrm{CK}=$ Water control group, $\mathrm{Pico}=$ picoxystrobin, Pyro = pyraclostrobin, and a.i. = active ingredient.

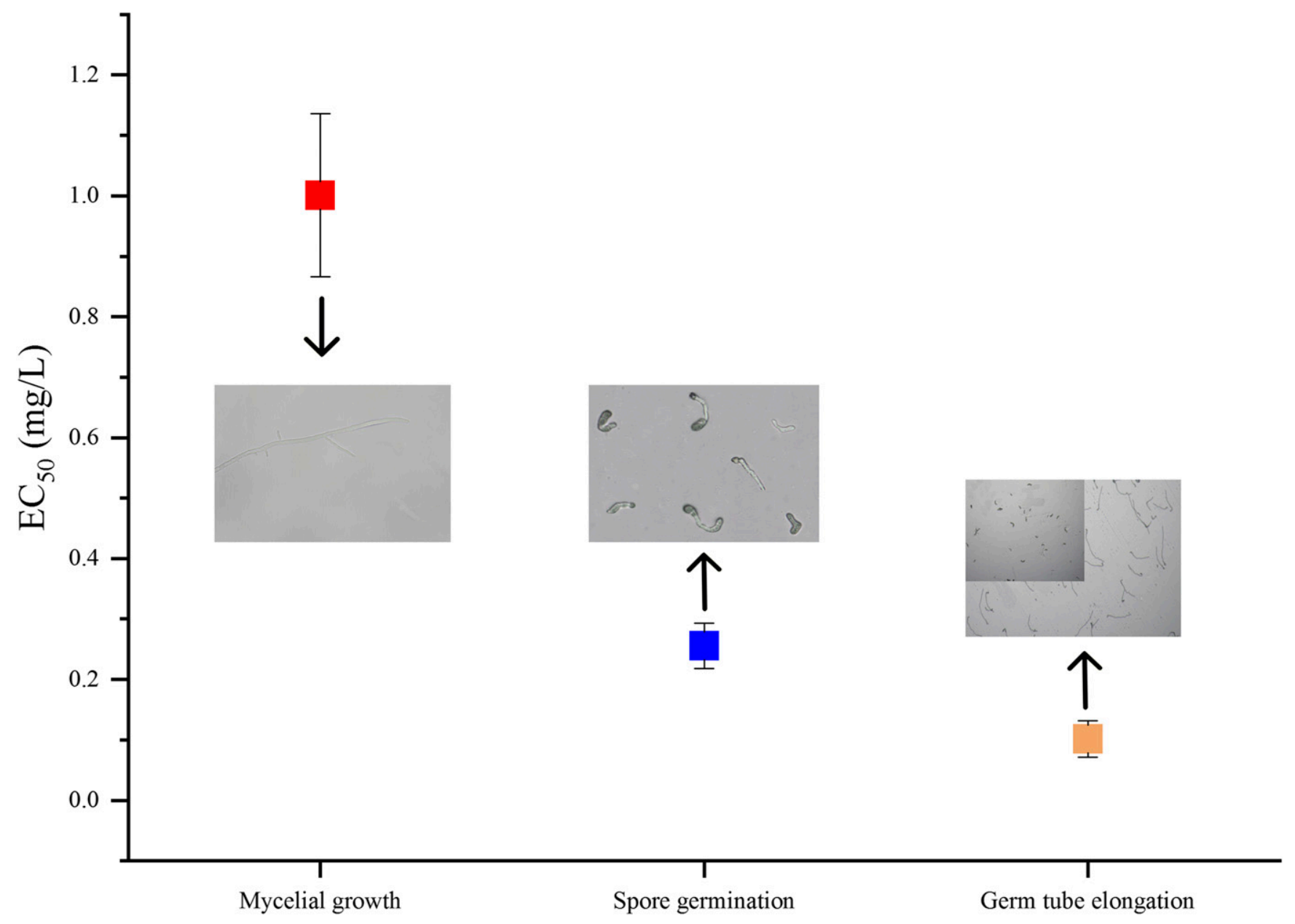

Fig. 4. Inhibitory activity of BF-500-3, the metabolite of pyraclostrobin, against Colletotrichum scovillei. $\mathrm{EC}_{50}=$ half maximal effective concentration. 
setting. Application of pyraclostrobin initiated at the full-bloom stage had the highest yield of 27.39 to $31.98 \mathrm{t} / \mathrm{ha}$, which may be attributable to the favorable efficacy and stimulatory effect of the fungicide.

Final residue analysis of pyraclostrobin, BF-500-3, and picoxystrobin in pepper. The residual level of tested fungicides increased with increasing application dosage. The terminal residues of pyraclostrobin, picoxystrobin, and BF-500-3 were 0.160 to 0.394 , 0.216 to 0.235 , and 0.080 to $0.195 \mathrm{mg} / \mathrm{kg}$ when applied at different application timing and dosages and were lower than the maximum residue limits (MRLs) established by the European Union (pyraclostrobin, $0.5 \mathrm{mg} / \mathrm{kg}$; picoxystrobin, $0.5 \mathrm{mg} / \mathrm{kg}$ ), which demonstrated that fungicide applied at all tested dosages and timing is safe (Fig. 8).

Control efficacy of fungicide mixtures against pepper anthracnose in the field. The mixtures of pyraclostrobin with fludioxonil, tebuconazole, thiophanate-methyl, and carbendazim provided better control efficacy than did pyraclostrobin alone (Fig. 9). Pyraclostrobin applied at $120 \mathrm{~g}$ of a.i./ha showed control efficacy ranging from 64.27 to $66.79 \%$ during 2016 and 2017, whereas the addition of the other four fungicides into the spray mixtures had efficacy ranging from 69.87 to $71.30,72.68$ to $78.36,66.95$ to 67.71 , and 66.01 to $67.30 \%$, respectively, which exhibited no significant difference with pyraclostrobin applied alone. The addition of fungicides with different modes of action can decrease the application dosage of pyraclostrobin and reduce the risk of fungicide resistance development in $C$. scovillei.

\section{Discussion}

Fungicide resistance monitoring has great significance for the appropriate use of fungicides and establishes a basis for the development

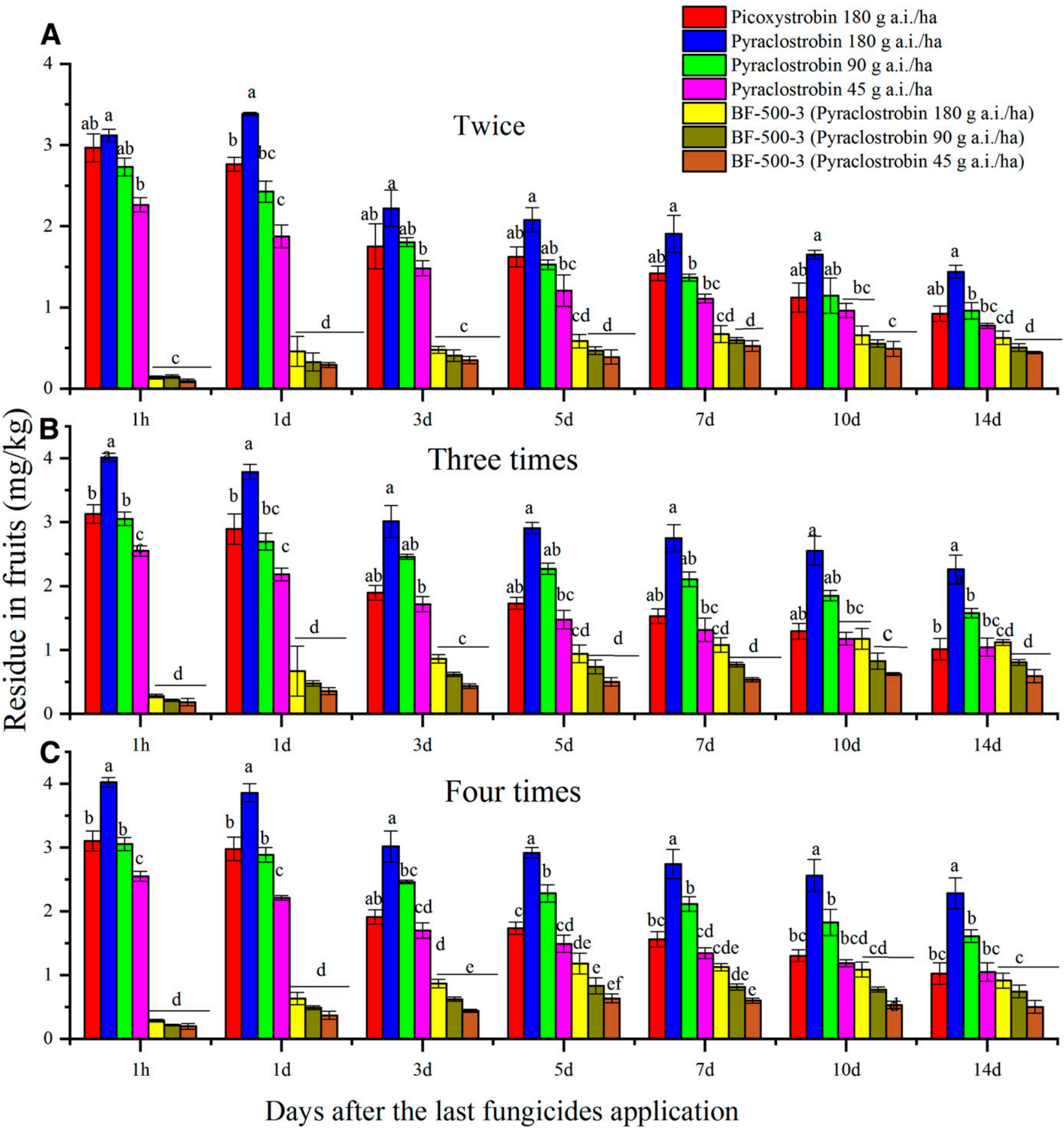

Fig. 6. The residues of pyraclostrobin, picoxystrobin, and BF-500-3 in pepper fruits after A, two, B, three, and C, four applications. a.i. = active ingredient. The bars with different lowercase letters indicate significant difference. 
of sustainable agriculture. Pyraclostrobin was introduced to control pepper anthracnose in 2017, but it has not been widely used in pepper. Previous studies demonstrated that Botrytis cinerea, Ascochyta rabiei, and Alternaria alternata have developed resistance to pyraclostrobin (Avenot and Michailides 2007; Kim and Xiao 2010; Wise et al. 2009), which suggests that we should monitor the sensitivity development of $C$. scovillei to this fungicide. Our results indicated that compared with the baseline sensitivity data (Gao et al. 2017), no significant difference in sensitivity of $C$. scovillei collected from 2016 and 2017 to pyraclostrobin was observed. A few abnormal $\mathrm{EC}_{50}$ values had no effect on the sensitivity distribution, but we should continue to monitor sensitivity changes of $C$. scovillei to pyraclostrobin. These results are meaningful for providing guidance for pepper production and fungicide applications.

In pepper production, farmers applied fungicides starting at the fruit stage with a spraying interval of 5 to 7 days to protect fruit from fungal infection. Fungicide was applied $>10$ times, which increased production cost and promoted the risk of environmental pollution. Moreover, the overuse of fungicide may not be beneficial for increasing yield. Determination of fungicide application timing in controlling anthracnose is critical for promoting the sustainable development of the pepper industry (Mueller et al. 2009). Optimal fungicide application timing is determined by various parameters. Among them, the environmental conditions and occurring characteristics of the disease are the main factors (Mudita and Kushalappa 1993). Colletotrichum species can cause latent infection flowers that are the only organ often infected by fungi with a low severity of anthracnose. In July (the growing season of pepper fruits), weather conditions including abundant rainfall, long periods of high temperature, and humidity could favor spore germination and fungal infection on fruit, thus accelerating disease occurrence (Peres et al. 2005; Talhinhas et al. 2010). Abundant spores then appear on fruit, which promotes secondary infection. This study confirmed that preventing the initial infection sources is critical for pepper anthracnose management. In this study, efforts were made to incorporate low fungicide cost into the selection of fungicide application timing for effective prevention of pepper anthracnose. Fungicides applied during the full-bloom period not only provided more satisfactory efficacy but also delayed anthracnose disease onset (no symptoms on greenripening fruit), prevented the spread of pathogenic fungi, and increased the pepper yield. However, fungicide applications started at the early green-ripening stage did not prevent the spread of disease in time, which demonstrated that anthracnose occurrence and severity had a strong relationship with the primary infection source. The experiments also indicated that if fungicide applications started at flowering, the next application could be delayed to the mature green stage without redundant fungicide use. Thus, determination of the suitable application timing is important for promoting the sustainable management of disease and obtaining better economic benefits. Structural equation modeling also indicated that fungicide application timing plays a dominant role in anthracnose disease severity compared with other factors, including application dosage,

$-3.195^{*}$

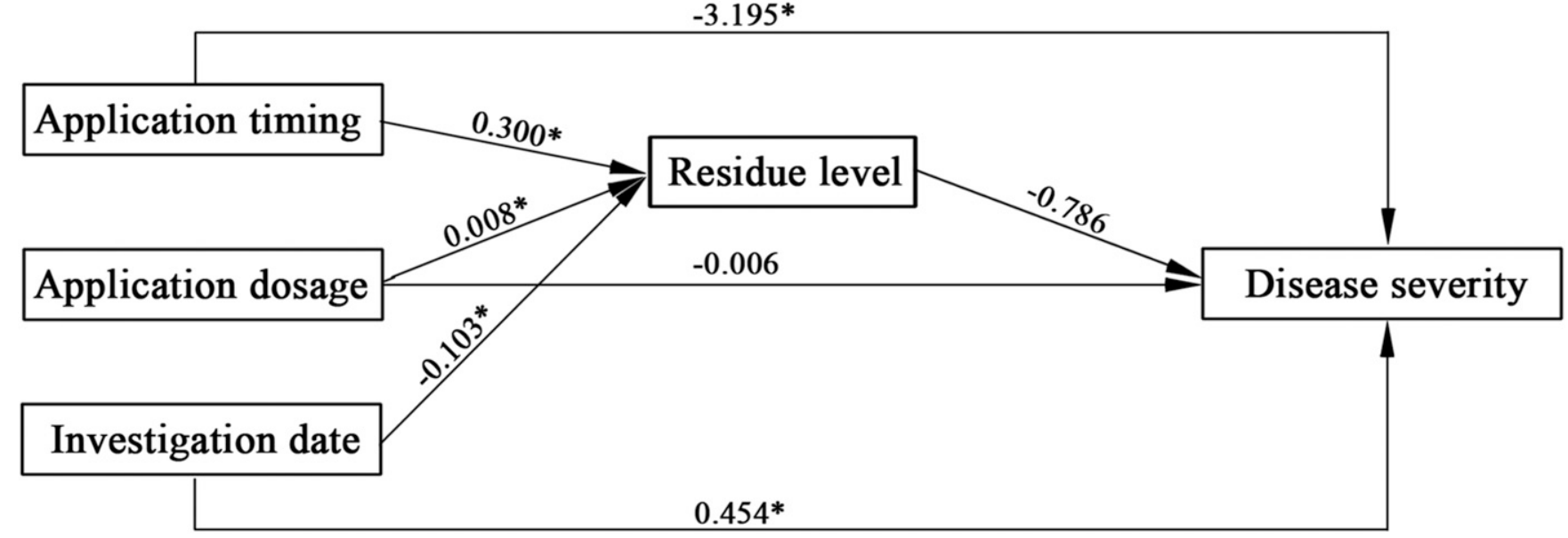

Fig. 7. Structural equation models for assessment of the relationship among application timing, dosage, investigation date, residue level, and anthracnose disease severity. ${ }^{*} P<0.001$

Table 1. Effect of different application timing on fruit growth parameters and yield in the field

\begin{tabular}{|c|c|c|c|c|c|c|}
\hline Treatment $^{\mathbf{x}}$ & Dose (g of a.i./ha)y & Chili/plant $(n)^{\mathrm{z}}$ & Length/fruit (cm) & Width/fruit (cm) & Weight/fruit (g) & Yield (t/ha) \\
\hline \multicolumn{7}{|c|}{ Pyraclostrobin } \\
\hline \multirow[t]{3}{*}{ II } & 180 & $62.00 \mathrm{ab}$ & $5.29 \mathrm{a}$ & $1.05 \mathrm{a}$ & $2.56 \mathrm{ab}$ & $26.89 \mathrm{ab}$ \\
\hline & 90 & $61.25 \mathrm{ab}$ & $5.23 \mathrm{a}$ & $1.10 \mathrm{a}$ & $2.49 \mathrm{ab}$ & $25.82 \mathrm{ab}$ \\
\hline & 45 & $60.70 \mathrm{ab}$ & $5.20 \mathrm{a}$ & $1.05 \mathrm{a}$ & $2.46 \mathrm{ab}$ & $25.24 \mathrm{ab}$ \\
\hline \multirow[t]{3}{*}{ III } & 180 & $63.40 \mathrm{ab}$ & $5.41 \mathrm{a}$ & $1.11 \mathrm{a}$ & $2.72 \mathrm{ab}$ & $28.92 \mathrm{ab}$ \\
\hline & 90 & $62.35 \mathrm{ab}$ & $5.33 \mathrm{a}$ & $1.11 \mathrm{a}$ & $2.57 \mathrm{ab}$ & $26.90 \mathrm{ab}$ \\
\hline & 45 & $61.60 \mathrm{ab}$ & $5.32 \mathrm{a}$ & $1.17 \mathrm{a}$ & $2.45 \mathrm{ab}$ & $26.05 \mathrm{ab}$ \\
\hline \multirow[t]{3}{*}{ IV } & 180 & $64.10 \mathrm{a}$ & $5.53 \mathrm{a}$ & $1.18 \mathrm{a}$ & $2.88 \mathrm{a}$ & $31.98 \mathrm{a}$ \\
\hline & 90 & $62.80 \mathrm{ab}$ & $5.41 \mathrm{a}$ & $1.20 \mathrm{a}$ & $2.70 \mathrm{a}$ & $28.79 \mathrm{ab}$ \\
\hline & 45 & $62.10 \mathrm{ab}$ & $5.32 \mathrm{a}$ & $1.10 \mathrm{a}$ & $2.69 \mathrm{a}$ & $27.39 \mathrm{ab}$ \\
\hline \multicolumn{7}{|l|}{ Picoxystrobin } \\
\hline II & 180 & $61.1 \mathrm{ab}$ & $5.15 \mathrm{a}$ & $1.07 \mathrm{a}$ & $2.46 \mathrm{ab}$ & $25.17 \mathrm{~b}$ \\
\hline III & 180 & $61.85 \mathrm{ab}$ & $5.08 \mathrm{a}$ & $1.05 \mathrm{a}$ & $2.45 \mathrm{ab}$ & $25.29 \mathrm{ab}$ \\
\hline IV & 180 & $61.80 \mathrm{ab}$ & $5.16 \mathrm{a}$ & $1.05 \mathrm{a}$ & $2.68 \mathrm{ab}$ & $27.93 \mathrm{ab}$ \\
\hline CK & - & $58.95 \mathrm{~b}$ & $4.96 \mathrm{a}$ & $1.10 \mathrm{a}$ & $2.41 \mathrm{~b}$ & $24.75 \mathrm{~b}$ \\
\hline
\end{tabular}

${ }^{x}$ II, III, and IV indicate the mean number of fungicide applications. CK $=$ Water control group.

$\mathrm{y}$ a.i. = active ingredient.

${ }^{\mathrm{z}}$ Columns with different lowercase letters indicate significant difference. 
investigation date, and residue level. In addition, these results provide a foundation for exploring the epidemiology of Colletotrichum species in pepper fields.

Pyraclostrobin, a commonly used fungicide, has high efficacy against anthracnose in strawberry (Mikulic-Petkovsek et al. 2013; Turechek et al. 2006), soybean (Chen et al. 2011), and cucumber (Wang et al. 2014). In this study, pyraclostrobin also showed better efficacy against pepper anthracnose than picoxystrobin, which may

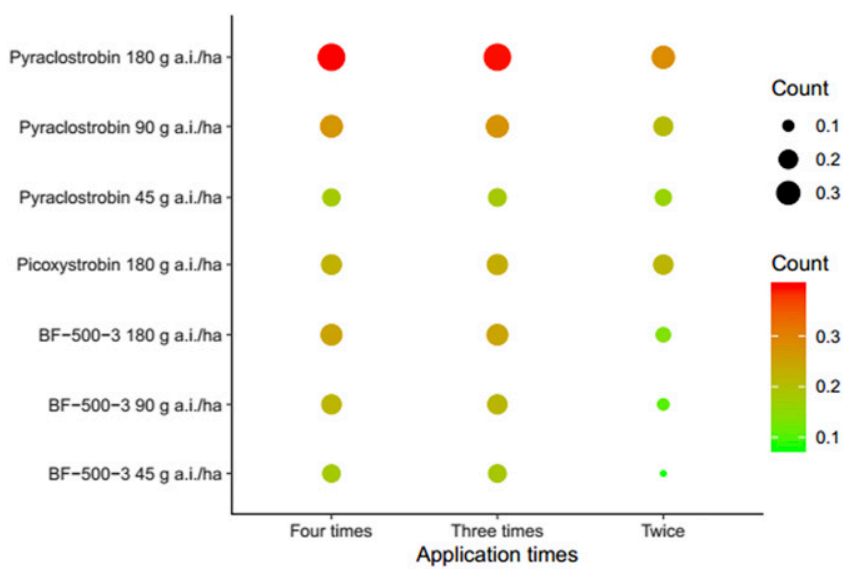

Fig. 8. The final residues of pyraclostrobin, picoxystrobin, and BF-500-3 in pepper fruits. a.i. $=$ active ingredient. be related to various factors. Among them, the high inhibitory activity of pyraclostrobin and its metabolite BF-500-3 might be one of the most important reasons. Moreover, the strong local absorption of pyraclostrobin could also improve the efficacy of the fungicide. However, after 7 days of fungicide application, disease severity sharply increased and residue level decreased, mainly owing to the photodegradation of pyraclostrobin (Guan et al. 2015). The poor water-soluble characteristics of pyraclostrobin have resulted in rainfall having little impact on its dissipation ( $\mathrm{Li}$ et al. 2017). In addition, the terminal residues of pyraclostrobin, picoxystrobin, and BF-500-3 were much lower than the MRLs established by the European Union (pyraclostrobin, $0.5 \mathrm{mg} / \mathrm{kg}$; picoxystrobin, $0.5 \mathrm{mg} / \mathrm{kg}$ ). These results indicated that the application of pyraclostrobin and picoxystrobin at the appropriate timing and dosage can exert their maximum potential to protect peppers from fungi.

A previous study demonstrated that a mixture of pyraclostrobin with fludioxonil (1:1), tebuconazole (1:1), thiophanate-methyl (1: 3 ), and carbendazim (1:3) had a synergistic effect against mycelial growth and spore germination of $C$. scovillei (Gao et al. 2017). In our field trials, addition of the above fungicides into the tank mixtures showed no significant effect on pyraclostrobin efficacy because this fungicide had favorable efficacy when applied alone. Despite this fact, fungicide mixtures are of great value because they might reduce the risk of developing resistance of Colletotrichum spp. to pyraclostrobin and make up the defects of photodegradation of this fungicide (Shi et al. 2017).

In conclusion, fungicides applied at the flowering stage could destroy Colletotrichum spp. during their incubation period, reduce primary infection, as well as delay infection and decrease anthracnose occurrence.
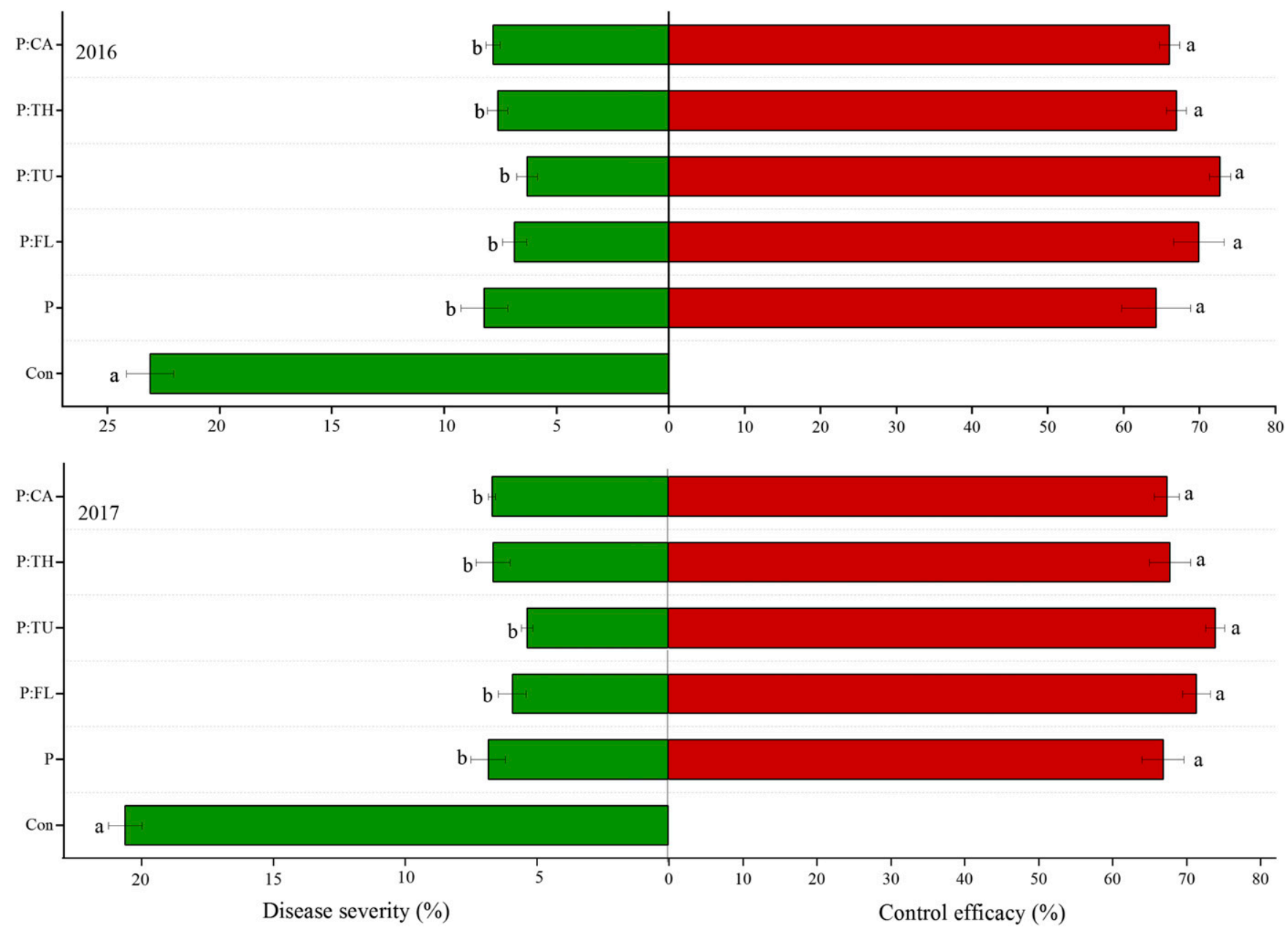

Fig. 9. The control (Con) efficacy of the mixtures of pyraclostrobin $(\mathrm{P})$ and fludioxonil (FL), tebuconazole (TU), thiophanate-methyl (TH), and carbendazim (CA) against anthracnose in the field. Bars with different lowercase letters indicate significant difference. 
Experimental data and structural equation modeling indicated that fungicide application timing had a significant effect on disease severity. The terminal residues of all tested fungicides were below MRLs that met food safety policies, and BF-500-3 (the major metabolite of pyraclostrobin) also had high activity against $C$. scovillei. The mixtures of pyraclostrobin with tebuconazole showed the highest efficacy against anthracnose. Although a few abnormal $\mathrm{EC}_{50}$ values had no effect on sensitivity distribution, continued sensitivity monitoring is necessary.

\section{Literature Cited}

Avenot, H. F., and Michailides, T. J. 2007. Resistance to pyraclostrobin, boscalid, and pristine (pyraclostrobin plus boscalid) in Alternaria alternata isolates from California pistachio. Phytopathology 97:S5-S5.

Beck, B., Spanoghe, P., Moens, M., Brusselman, E., Temmerman, F., Pollet, S., and Nuyttens, D. 2014. Improving the biocontrol potential of Steinernema feltiae against Delia radicum through dosage, application technique and timing. Pest Manag. Sci. 70:841-851.

Chen, Y., Zhang, A. F., Xia, B. Y., and Wang, W. X. 2011. Efficacy of pyraclostrobin in controlling soybean anthracnose and their effects on the health protection and yield increase. Agrochemicals 50:697-699.

Diao, Y. Z., Zhang, C., Liu, F., Wang, W. Z., Liu, L., and Cai, L. 2017. Colletotrichum species causing anthracnose disease of chili in China. Persoonia 38:20-37.

Food and Agriculture Organization of the United Nations. 2015. FAOSTAT: Food and agriculture data. http://faostat.fao.org/

Forster, W. A., Zabkiewicz, J. A., and Liu, Z. 2006. Cuticular uptake of xenobiotics into living plants. part 2: Influence of the xenobiotic dose on the uptake of bentazone, epoxiconazole and pyraclostrobin, applied in the presence of various surfactants, into Chenopodium album, Sinapis alba and Triticum aestivum leaves. Pest Manag. Sci. 62:664-672.

Fulcher, J. M., Wayment, D. G., White, P. M., and Webber, C. L. 2014. Pyraclostrobin wash-off from sugarcane leaves and aerobic dissipation in agricultural soil. J. Agric. Food Chem. 62:2141-2146.

Gao, Y. Y., He, L. F., Li, B. X., Jin, L., Wei, M., and Feng, L. 2017. Baseline sensitivity to pyraclostrobin of Colletotrichum acutatum species complex collected from chili in Shandong Province and the screening of synergistic formula. Chin. J. Pestic. Sci. 19:701-707.

Guan, L., Zhang, P., Wang, X. K., Ren, Y. P., Guo, B. B., and Liu, F. 2015. Photodegradation of pyraclostrobin in water environment and microencapsulation effect on its photostability. J Agro-Environ. Sci 34:1493-1497.

Harp, T., Kuhn, P., Roberts, P. D., and Pernezny, K. 2014. Management and crossinfectivity potential of Colletotrichum acutatum causing anthracnose on bell pepper in Florida. Phytoparasitica 42:31-39.

Harp, T. L., Pernezny, K., Ivey, M. L. L., Miller, S. A., Kuhn, P. J., and Datnoff, L. 2008. The etiology of recent pepper anthracnose outbreaks in Florida. Crop Prot. 27:1380-1384.

Kim, C. H., and Park, K. S. A. 1988. Apredictive model of disease progression of red-pepper anthracnose. Plant Pathol. J. 4:325-331.

Kim, Y. K., and Xiao, C. L. 2010. Resistance to pyraclostrobin and boscalid in populations of Botrytis cinerea from stored apples in Washington State. Plant Dis. 94:604-612.

Kwon, C. S., and Lee, S. G. 2002. Occurrence and ecological characteristics of red pepper anthracnose. Res. Plant Dis. 8:120-123.

Lewis Ivey, M. L., Navadiaz, C., and Miller, S. A. 2004. Identification and management of Colletotrichum acutatum on immature bell peppers. Plant Dis. 88:1198-1204.

Li, B. X., Wang, W. C., Zhang, X. P., Ren, Y. P., Gao, Y., Mu, W., and Liu, F. 2017. Using coordination assembly as the microencapsulation strategy to promote the efficacy and environmental safety of pyraclostrobin. Adv. Funct. Mater. 27:1701841.
Lin, Q., Lv, Z., and Huang, R. 2004. Screening of pepper germplasm for resistance to TMV, CMV, Phytophthora blight and anthracnose. Southwest China J. Agric. Sci. 18:108-110.

Lin, S., and Hand, F. P. 2019. Investigations on the timing of fruit infection by fungal pathogens causing fruit rot of deciduous holly. Plant Dis. 103:308-314.

Mikulic-Petkovsek, M., Schmitzer, V., Slatnar, A., Weber, N., Veberic, R., and Stampar, F. 2013. Alteration of the content of primary and secondary metabolites in strawberry fruit by Colletotrichum nymphaeae infection. J. Agric. Food Chem. 61:5987-5995

Mudita, I. W., and Kushalappa, A. C. 1993. Ineffectiveness of the first fungicide application at different initial disease incidence levels to manage Septoria blight in celery. Plant Dis. 77:1081-1084.

Mueller, T. A., Miles, M. R., Morel, W., Marois, J. J., Wright, D. L., Kemerait, R. C., Levy, C., and Hartman, G. L. 2009. Effect of fungicide and timing of application on soybean rust severity and yield. Plant Dis. 93:243-248.

Peres, N. A., Timmer, L. W., Adaskaveg, J. E., and Correll, J. C. 2005. Lifestyles of Colletotrichum acutatum. Plant Dis. 89:784-796.

Shi, K. W., Wu, X. J., Ma, J. W., Zhang, J. F., Zhou, L., Wang, H., and Li, L. 2017 Effects of planting and processing modes on the degradation of dithianon and pyraclostrobin in Chinese yam (Dioscorea spp.). J. Agric. Food Chem. 65: 10439-10444.

Takushi, T., Kadekaru, K., and Arasaki, C. 2014. Occurrence of strobilurinresistant strains of Colletotrichum gloeosporioides, the causal fungus of mango anthracnose [in Japanese with English abstract]. Jpn. J. Phytopathol 80:119-123.

Takushi, T., Taba, S., and Moromizato, Z. 2013. Latent infection on fruits and infection period of mango anthracnose fungi, Colletotrichum gloeosporioides and C. acutatum in a rainout shelter. Jpn. J. Phytopathol 79:142-149.

Talhinhas, P., Mota-Capitão, C., Martins, S., Ramos, A. P., Neves-Martins, J., Guerra-Guimarães, L., Várzea, V., Silva, M. C., Sreenivasaprasad, S., and Oliveira, H. 2010. Epidemiology, histopathology and aetiology of olive anthracnose caused by Colletotrichum acutatum and C. gloeosporioides in Portugal. Plant Pathol. 60:483-495.

Turechek, W. W., Peres, N. A., and Werner, N. A. 2006. Pre- and post-infection activity of pyraclostrobin for control of anthracnose fruit rot of strawberry caused by Colletotrichum acutatum. Plant Dis. 90:862-868.

Wang, J. G., Zhao, S. F., Xu, Y. H., Hu, X. X., Ke, H. Y., and Hong, Z. H. 2014. Field effect test and security analysis of pyraclostrobin on strawberry, balsam pear and cucumber anthracnose. Chin. Hortic Abstr. 5:56-58.

Wise, K. A., Bradley, C. A., Pasche, J. S., and Gudmestad, N. C. 2009. Resistance to QoI fungicides in Ascochyta rabiei from chickpea in the Northern Great Plains. Plant Dis. 93:528-536.

Xia, H., Zhu, H. J., Zhou, Q., and Gao, B. D. 2012. Pathogen identification of a new anthracnose of pepper in Zhijiang, Hunan. Acta Phytopathologica Sin. 42:120-125.

Xu, X. F., Lin, T., Yuan, S. K., Dai, D. J., Shi, H. J., and Zhang, C. Q. 2014 Characterization of baseline sensitivity and resistance risk of Colletotrichum gloeosporioides complex isolates from strawberry and grape to two demethylationinhibitor fungicides, prochloraz and tebuconazole. Australas. Plant Pathol. 43: 605-613.

You, X. W., Liu, C. Y., Liu, F. M., Liu, Y. P., and Dong, J. N. 2012. Dissipation of pyraclostrobin and its metabolite BF-500-3 in maize under field conditions Ecotoxicol. Environ. Saf. 80:252-257.

Young, J. R., Tomaso-Peterson, M., Tredway, L. P., and de la Cerda, K. 2010. Occurrence and molecular identification of azoxystrobin-resistant Colletotrichum cereale isolates from golf course putting greens in southern United States. Plant Dis. 94:751-757.

Yu, S. M., Ramkumar, G., and Lee, Y. H. 2013. Light quality influences the virulence and physiological responses of Colletotrichum acutatum causing anthracnose in pepper plants. J. Appl. Microbiol. 115:509-516. 